\title{
ICM 2018 in Rio - A Personal Account Part II
}

Ulf Persson (Chalmers University of Technology, Göteborg, Sweden), Editor of the EMS Newsletter

This article is the second part of the personal account of the author who attended the ICM2018 in Rio. Since Part I of the report triggered a number of reactions I suggest that readers consult the section Letters to Editor (p. 59) for the comments by M. Viana, Chairman of the IMC2018 organising committee, V. Mehrmann, President of EMS, and a reply by $U$. Persson.

The EMS Newsletter is open for other remarks focused on the value for our community of the IMU congresses of mathematicians.

Note that the views expressed in the Newsletter are those of the authors and do not necessarily represent those of the EMS or the Editorial Team.

The Editor-in-Chief

\section{Daily life at the congress}

The days at a congress tend to be very similar to each other, as they are from one Congress to another. There are of course the talks, which serve the same purpose as food at a social gathering. It is not food which is the main thing, but getting together; however, without the former, the latter would be a bit harder. Mathematical talks are either of the show variety or seriously meant to convey both conceptual ideas and technical information, although one should of course be wary of drawing too precise a line between them: all talks have at least a little of both. A serious talk has a very narrow audience and is typically given at specialised conferences. As noted, one complaint about an ICM I have often heard over the years is that it does not have much to offer the professional mathematicians, who instead give priority to their specialised meetings in their own fields. Not much can be done about that obviously, as an ICM has a different ambition, namely to create a feeling of community including all mathematicians, thus the show talks are the order of the day, trying to address all mathematicians rather than just experts. There are of course the prestigious plenary talks taking place in the main hall, then there are invited speakers who will have to make do with smaller halls, while the "self-invited" are reduced to short communications or poster sessions. This is typical for meetings at big science.

The plenary talks get most attention and are reviewed by mathematicians as if they were movies. As movies most of them fall short of expectations. There are real showmen among mathematicians who love to perform and never give a boring talk. Atiyah is the outstanding example. At 89 he is still going strong ${ }^{1}$ and he carried off by virtue of charm and authority a talk you and I would have been booed off of the stage for had we attempted it. But most mathematicians have no such talents, nor ambi- tions for that matter. Nevertheless, in my opinion there were some very good talks, and, unlike in many other disciplines, mathematicians tend to be intellectually very honest and there is seldom a talk without at least some palpable content. However, the organisers had decided not to print out any programmes, instead providing apps. At least for older people like me, this was a definite disadvantage, and made me miss many talks.

Another source of entertainment is to browse among the various bookstalls, but with the advent of laptops and smartphones there are no longer computer rooms set up, which I recall from Beijing and Madrid. Nevertheless, the organisers had thoughtfully decided to provide a few laptops on a couple of tables in the hall of the publishers. I actually found that very helpful, especially as they were not in high demand so you could easily access them.

Then, more excitingly, there is a life of parties and receptions, to which I fear most participants are not privy. I myself only got a glimpse of it through my invitations by the Norwegians, who have made a mathematical claim with the Abel Prize, arranging an Abel lecture at each Congress. This time I was also invited to the reception of the London Mathematical Society. Both of these receptions took place at the same location (but of course at different times), as well as many other similar events, I surmise; namely at the so-called i-bar room on the top floor of the Mercure hotel, just next to the venue, and where all of the VIPs had been offered accommodation. The room provided splendid views of the Atlantic Ocean and one could also imagine the presence of the big city just behind the horizon. ${ }^{2}$ I suspect I only went to the lower circles of 'Paradiso'.

\section{Meeting Marcelo Viana, the Chairman of the Organising Committee}

I have been speculating above ${ }^{3}$ about the congress, especially the fire. How much did it really affect it? Maybe the emptiness of the customary bags you always receive at the registration could be due to the fire, their contents having been devoured by it. Incidentally, I wonder how far this tradition of giving out bags goes back? Did Hilbert carry one with the logo of the ICM Paris in 1900? More generally, could all of the perceived shortcomings of the present Congress be due to the fire? Presenting

\footnotetext{
1 As of the time of writing. Sadly we all know that he passed away on January 11 this year.

2 How far away? Could it have been on the tenth floor, say 30 meters above ground, a quick estimate gives $20 \mathrm{~km}$, somewhat short of the distance to the centre.

3 See Part I of my personal account (Newsletter 111).
} 
myself as an editor of the EMS Newsletter (which is true) with an assignment to cover the Congress (which may be stretching truth a little, but can be retroactively confirmed with this article), I did get prompt access to the Chairman of the Organising Committee by the name of Marcelo Viana. He happily received me with a very warm smile, commiserating as I limped in, having run to the appointment, fearful of keeping him waiting, and as a consequence stretching a muscle. No need to have hurried, he assured me, being in a good mood, which he later revealed, on the promise of temporary secrecy, was due to the fact that the replacement for the stolen medal was underway.

'Don't blame the fire, blame me!' he disarmingly exclaimed when I brought up the case of the fire and its possibly devastating effects on the congress. In fact, the effects of the fire had been greatly exaggerated, I was told, it was actually not much of an interruption. It started on the evening of July the 29th (therefore just before my arrival the following morning) but was quickly put out. It was due to a hot air balloon touching the building in which the congress kept some equipment. The fire never went beyond licking the outside of the same; everything inside was unscathed. However, flying a balloon requires special permission in Brazil and is otherwise illegal, so a police investigation was necessary. Consequently, the building was cordoned off and became off limits during the investigation. Inside they had stored their video equipment to be used for the ceremony and the plenary talks, and they were forced to rent new gadgets and set it up: a process which had initially taken a week and now had to be performed in 48 hours. It certainly was hard work, but it worked out in the end (indeed, so perfectly that no one noticed, I reflected, but that is typical of competent management, great things being done silently with no visible effects). And otherwise the running of the congress was not effected in any way. The bags were empty not because their contents had perished in some putative fire, but because they had never existed. (If paperless congresses will be the case in the future, maybe the tradition to hand them out will be discontinued?)

A decision had been taken to dispense with paper for ecological reasons. So much paper was simply being discarded by the participants, who now more and more have come to rely on digital means. Maybe a wrong decision, he admitted modestly, the next congress may decide to reintroduce paper in the form of programmes, daily newsletters and such things, but it was ecologically a sound one, he maintained. Maybe, but paper, which by the way is biodegradable, makes up for but a tiny fraction of the ecological footprint caused by a congress; one need only think about what it takes to transport the bulk of the participants halfway across the globe. Instead, they had provided apps to be downloaded, and if your phones did not operate in Brazil, or at a prohibitive cost, there would of course always be the home page (it is notoriously difficult to navigate home pages in my experience, but that could be due to my age) and if you did not lug around your laptop there were TV-monitors everywhere, I was told. But the problems with the latter, I thought, was that they showed all kinds of footage and you had to stand and wait until the daily programme showed up (if ever). I never saw one displayed on a screen, but maybe I lacked the necessary patience? And then a TV monitor cannot be put into your pocket (unless it is in the form of a phone). But of course, digital programmes and newsletters can be continually updated; the advantages of the digital approach are obvious and easy to formulate, while the disadvantages are less so, and harder to put in words. But then in the end, it may simply boil down to being of an older generation formed by outdated habits. Yet, he conceded, he also prefers physical books, but he doubts that someone like Avila ever checked out a book in the library, although of course mathematicians in general tend to be conservative and like books, maybe, I reflect, as they have the pretensions of writing for posterity, sometimes even for eternity, not just for the immediate future as people in big science.

As to the President not being present, that was just a coincidence into which I should not read too much, he admonished me (in particular not suspect that Brazilian society does not care about mathematics). The presence of the President was needed at a meeting of the World Bank, he explained, as Brazil is getting a new loan on very favorable terms, and this is good for mathematics as well, he added, concluding that he was very happy to have him there instead of here, where he could not have done much good.

As to security in Rio, he himself was scared when he visited New York in the 90s (it was much worse in the 70s when I lived there, I pointed out) and he was also afraid in Rio when he first moved here. But with care and avoiding the bad areas you are basically OK, and besides, what can you expect? it is a third world country after all with lots of poverty (this goes for India as well and it is comparatively safe, or am I naive?). But during the carnival, crime rates go down; people are out to enjoy themselves, on the other hand traffic accidents go up, he added. But as this is the most common way of coming to grief, I remarked, we have a high tolerance for it. And there are always reasons to worry, he continued, and used the example of the yellow fever warnings. Should participants be warned and vaccinations recommended? But that warning was issued in February, thus during summer. In winter, as it is now, there is no yellow fever, and besides you are only at risk in the countryside. He did not post it. Later on he relented due to some pressure from the health authorities. Better safe than sorry. And then he had to hurry to his next meeting. And I thought to myself that I never saw the yellow fever warning, shrugged my shoulders and limped out of the building.

\section{Tourism, or Rio by day}

Why fly a quarter of the way round the globe to Rio and not go there at all? Tourism, regardless of the purpose of your visit to an ICM, is an important component of it, if not necessarily the only one. If you cannot go by yourself you can join an organised tour. You may ordinarily scoff at such ventures if you fancy yourself to be an independent and adventurous traveller, but of course now you are 


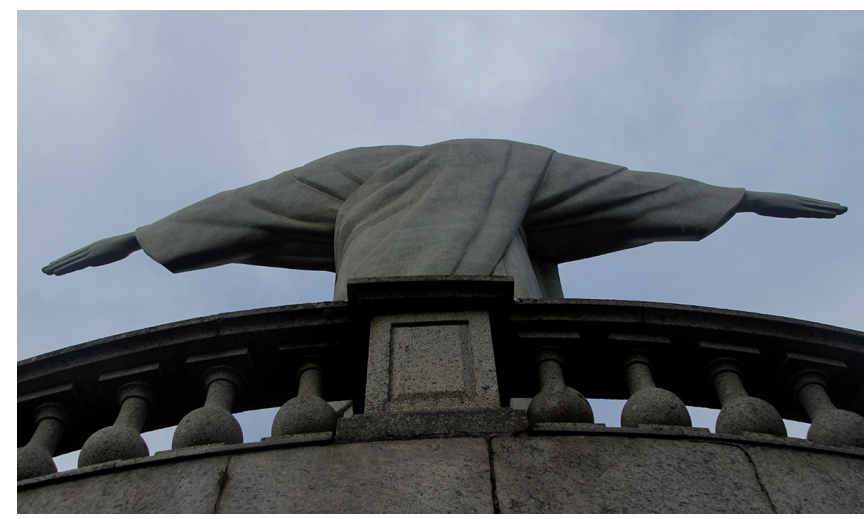

travelling with your colleagues: extending your attendance, if by other means. Three things come to mind to the tourist when thinking of Rio; namely, the Jesus statue, Sugar Loaf mountain and Copacabana beach. Pictures of the Jesus statute show it overlooking and dwarfing the city below, and thus one expects that it will present a dominating view wherever one is in the city. But big as it is, it is only 38 metres from the bottom of its pedestal to the crown of its head. Situated on the top of the mountain Corcovado, which rises 710 metres above the beach, it is about five kilometres from the centre itself, thus its apparent size is only about thirty minutes of arc, the same as that of the Sun or the Moon, and hence dwarfed in the general background. However, the view from above the mountain is spectacular and worth a trip, not just a detour. The Sugar Mountain, to which you can get access by two cable cars, is much closer to the centre, and offers a nice view of it, if not quite as spectacular. And we were told by the guide, the cable cars played an important role in a Bond movie from the early 70s. Both of these sights were offered on the standard Rio tour, but not Copacabana beach, immortalized, at least from the perspective of a mathematician, by Stephen Smale and Richard Feynman (most people would have other associations).

However, what I found more interesting was the excursion to Petropolis, which I took on the last day of the Congress. Petropolis is a city close to Rio but further inland and hence up in the mountains. I first encountered the name of the city in connection with the Austrian writer Stefan Zweig, who exiled himself there after the

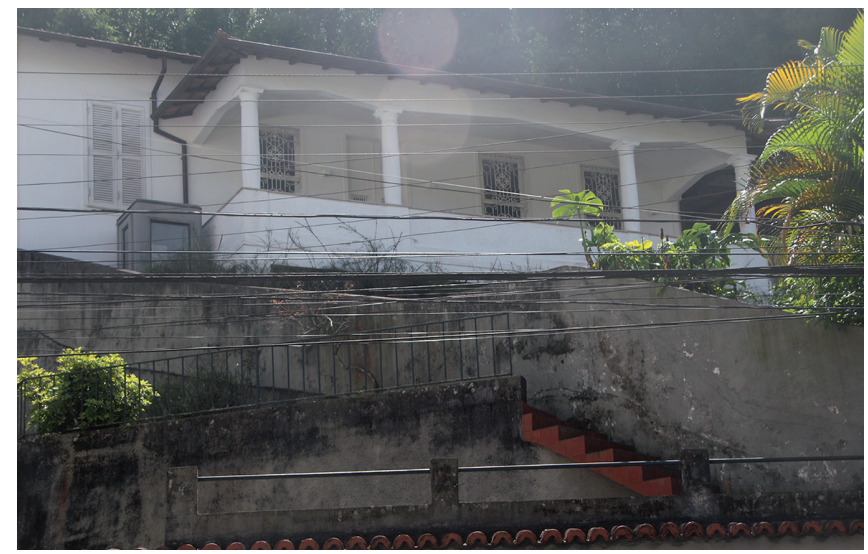

Casa Stefan Zweig, Petropolis.

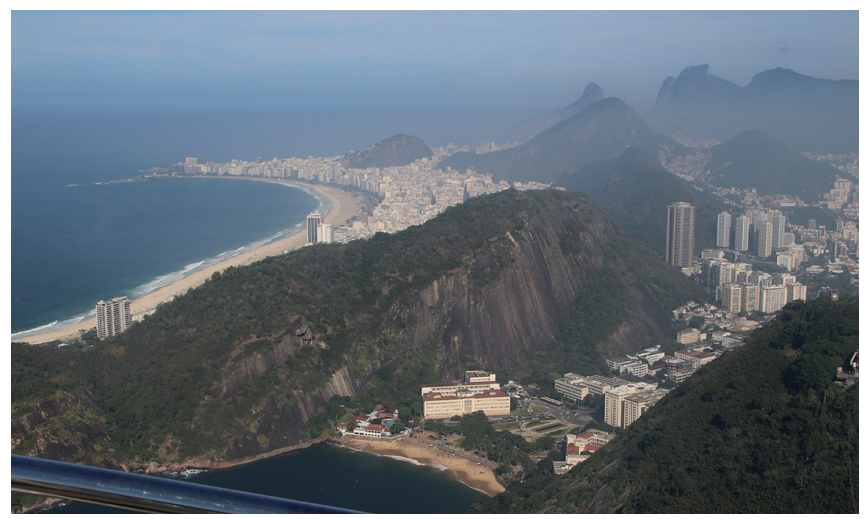

outbreak of the Second World War. His sojourn did not last more than a year and a half before he committed suicide in February 1942, together with his young wife and former secretary, out of depression concerning the war and the future of mankind (it is not clear whether his wife shared his existential misgivings, but she was apparently very loyal). In the 20 s and 30 s he was one of the most extreme bestselling writers in the world at a time when people read books much more than today, but after the war he descended into relative obscurity. However, in recent years his writing has had a modest revival due to sentimentality for the age in which he lived. In particular as he brings it to life in his autobiography Die Welt von Gestern (The World of Yesterday), completed the day before he died. Unfortunately, 'Casa Zweig' was closed the day we visited.

More interesting to most people may be the Imperial Palace in the city. Brazil had two emperors, Pedro I and his son Pedro II, something I have to admit I only learned during my visit. The first was originally a Portuguese Prince, who together with his family was in Brazilian exile during the Napoleonic Wars (Portugal and Sweden, along with Britain, were irreconcilable foes of Napoleonic France). He liked it so much that he refused to return to Portugal after Napoleon's downfall, and declared Brazil independent in 1822 and himself as its emperor. However, he abdicated in 1831, leaving the crown with his young son, not much more than a toddler. The son, however, turned out to be what we ideally expect of an exemplary monarch. A patron of the arts

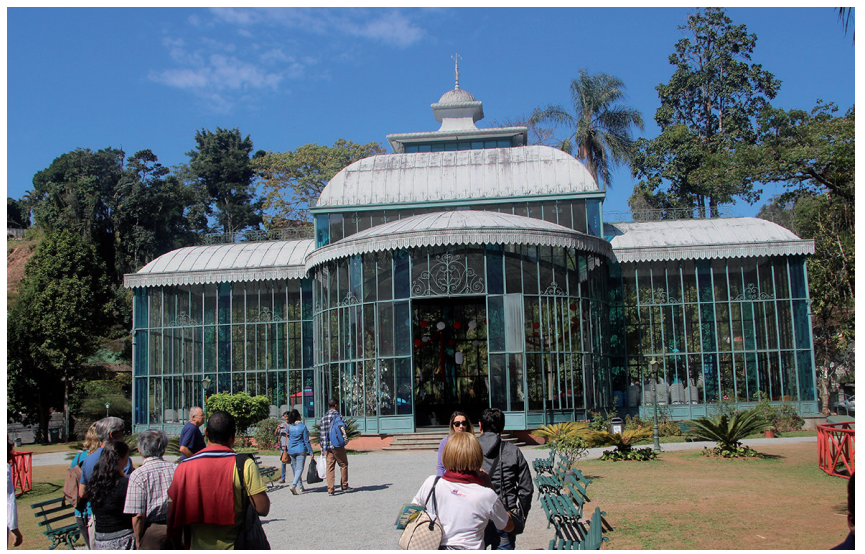

Crystal Palace, Petropolis. 
and sciences, a champion of liberal causes (in his case the abolition of slavery), he enjoyed widespread popularity. He was deposed in 1889, exiled himself to France and died two years later. The imperial connection during the 19th century left the city with a lot of interesting buildings, one particular and unexpected example being the replica of the Crystal Palace erected in London for the fabled 1851 exhibition, thus allowing oneself, be it in semi-tropical surroundings, temporary time travel back to mid 19th century London.

A day or so later I left Rio with an enhanced view of the country. The problem is the ridiculously low airfares of today, which not only enable but encourage frivolities such as weekend trips to New York. Ideally, a visit to Brazil would have started with a two week Atlantic crossing and then continued for at least a month or two. Air travel takes the romanticism out of travel, but the romantic scenario I am sketching is no longer an option in our age, except for individual cases (which of course in the past also held for exotic travel).

And as to ICMs. In spite of my grumblings I look forward, God willing, to visiting the next, adding St. Petersburg to the unbroken list of Beijing, Madrid, Hyderabad, Seoul and now Rio. In spite of the obvious disadvantages of a Congress they form a venerable tradition, which, as pointed out by Guillermo Curbera (a noted chronicler of the ICMs), is the envy of every other scientific discipline.

Ulf Persson is on the Editorial Board of the EMS Newsletter. His photo and CV can be found in previous Newsletter issues. 